\title{
Relationship between cells obtained by bronchoalveolar lavage and survival in idiopathic pulmonary fibrosis
}

Karin A Boomars, Sjoerd Sc Wagenaar, Paul G H Mulder, Heleen van Velzen-Blad, Jules $M M$ van den Bosch

\begin{abstract}
Background - The relationship between cell types in bronchoalveolar lavage (BAL) fluid and the clinical course of patients with idiopathic pulmonary fibrosis (IPF) has been the subject of several studies. However, the results of these studies are not conclusive. The aim of this study was to investigate the relationship between the absolute and relative cell numbers in BAL fluid from patients with IPF and their survival.

Methods - Results obtained from the initial BAL fluid analyses of all histologically proven cases of IPF $(n=49)$ were selected retrospectively. Cox's proportional hazards survival analysis was used for estimating the relationship between absolute and relative cell numbers and survival.
\end{abstract}

Results - A negative relationship was found between both the absolute numbers and percentages of eosinophils in BAL fluid samples and survival. No such relationship was demonstrated for the absolute numbers or the percentages of any other cell type.

Conclusions - Although this study has restrictions, these findings suggest a negative relationship between the absolute numbers and percentages of eosinophils in BAL fluid samples and survival in patients with IPF.

(Thorax 1995;50:1087-1092)

Keywords: idiopathic pulmonary fibrosis, bronchoalveolar lavage, interstitial lung disease.

Idiopathic pulmonary fibrosis (IPF) is a chronic, often progressive, interstitial lung disease. Although experimental studies have partly clarified several signalling mechanisms leading to the interstitial fibrotic process, an underlying cause for the accumulation of fibrous tissue has not been established. In lung biopsy specimens several cell types have been found in the interstitium as well as in the alveolar spaces. These cells are able to release various cell products including cytokines and toxic proteins which play a part in the inflammatory process, as well as in the proliferation of fibroblasts and collagen synthesis. Despite a difference in quality and quantity of the mediated cellular and extracellular components, the result of this ongoing reparative response, which originates in the interstitium, is often non-functioning tissue. The original architecture of pulmonary parenchyma is lost and replaced by fibrotic tissue with deformation of bronchioli.

In previous studies of bronchoalveolar lavage (BAL) fluid samples from patients with IPF, the total cell count was found to be increased compared with control subjects when the smoking status of both patients and controls was taken into account. ${ }^{1}$ Additionally, the percentages of polymorphonuclear neutrophils and eosinophils were also raised compared with control subjects. ${ }^{12}$ Results concerning the mast cell count in BAL fluid of patients with IPF compared with controls were not conclusive. ${ }^{3-6}$ No significant difference was demonstrated in the percentages of lymphocytes between patients with IPF and controls. ${ }^{12}$

To our knowledge, the relationship between BAL fluid analysis and survival in patients with IPF has been investigated in only one study. ${ }^{7}$ In this study no relationship was found between the BAL cell concentration, BAL cell percentages and survival. Several groups have investigated a possible relationship between absolute and relative numbers of various cell types in BAL fluid samples obtained from patients with IPF and the clinical course. Generally, BAL fluid lymphocytosis is associated with responsiveness to corticosteroid therapy and clinical improvement. ${ }^{8-10}$ Increased eosinophil and neutrophil counts without increased lymphocyte counts have been associated with failure to respond to treatment, ${ }^{8-11}$ however, this was not confirmed by all investigators. ${ }^{12}$ Increased histamine levels in BAL fluid correlated with more pronounced fibrosis in lung biopsy specimens of IPF patients, ${ }^{13}$ and results of experimental studies ${ }^{14}{ }^{15}$ suggest that mast cells may play a part in pulmonary fibrosis. The aim of this study was to investigate the relationship between the relative as well as the absolute cell numbers in BAL fluid samples obtained from patients with IPF and survival.

\section{Methods}

PATIENTS

The initial BAL fluid samples obtained from all patients with histologically proven IPF ( $\mathrm{n}=$ 49) were selected retrospectively from BAL fluid analyses $(n=2008)$ performed over a 10 year period between 1980 and 1990. All patients presented with dyspnoea, cough, or malaise. The mean age of the patients at which symptoms started was 56 years (range 30-73).

The diagnosis of IPF was based on compatible clinical information, evidence of diffuse 
Table 1 Characteristics of patients with idiopathic pulmonary fibrosis (IPF) and control subjects

\begin{tabular}{llllllll}
\hline Group & $n$ & $\begin{array}{l}\text { Mean age } \\
\text { (range) }\end{array}$ & Women & Men & $\begin{array}{l}\text { Non- } \\
\text { smokers }\end{array}$ & Smokers & Prednisone \\
\hline IPF & 49 & $56(30-73)$ & 21 & 28 & 31 & 18 & 22 \\
Controls & 30 & $33(21-55)$ & 15 & 15 & 15 & 15 & 0 \\
\hline
\end{tabular}

parenchymal infiltrates on chest radiography and, in most patients, restrictive lung function tests. Patients with significant environmental or occupational exposure, a history of ingestion of fibrogenic drugs, extrinsic allergic alveolitis, left ventricular failure, or collagen vascular diseases were excluded. Lung tissue for histological confirmation of the diagnosis of IPF was obtained by open lung biopsy.

BAL is routinely used in our unit in all patients who are suspected of interstitial lung disease. Twenty two patients were receiving corticosteroid therapy at the time BAL was performed (mean $9 \cdot 1 \mathrm{mg}$ daily). These patients had either been referred to our clinic after being treated in another centre, or IPF had been diagnosed before BAL was performed in our hospital. None of the patients was treated with cytotoxic drugs at the time BAL was performed. Only one patient received cyclophosphamide therapy, which was ended four months prior to BAL. The median time between start of symptoms and BAL was 3.0 years (mean 4.4 years).

In order to evaluate differences in the cellular analysis of BAL fluid samples between the IPF patients and healthy individuals, data obtained from BAL fluid analysis of control subjects were used. The control group consisted of 30 healthy normal volunteers. In both groups the smoking history was taken into account. Smokers were current smokers at the time BAL was performed. Non-smokers were subjects who did not smoke at the time of lavage or within at least six months before BAL; 15 of the 31 non-smoking patients were lifelong nonsmokers, and 16 were former smokers (the mean time between giving up smoking and BAL was 8.3 years, the median time 6.0 years). The characteristics of the patients and control subjects are listed in table 1 . This study was approved by the ethics committee of our hospital.

\section{BRONCHOALVEOLAR LAVAGE}

Bronchoalveolar lavage was performed as previously reported during fibreoptic bronchoscopy. ${ }^{2}$ Blood samples were taken at the time of lavage. In brief, the lavage procedure was as follows. After premedication with atropine and sometimes diazepam or codeine, and local anaesthesia of the larynx and bronchial tree with $0.5 \%$ tetracaine, BAL was performed by standardised washing of the middle lobe with four $50 \mathrm{ml}$ aliquots of sterile saline solution $(0.9 \% \mathrm{NaCl})$ at room temperature. Lavage fluid samples, kept on ice in a siliconised specimen trap, were centrifuged $(10 \mathrm{~min}$, $350 \mathrm{~g}$ ) and separated into cells and supernatant. Cells from the last three aliquots were pooled, washed twice, counted, and suspended in minimal essential medium (Gibco, Grand Island, New York, USA) supplemented with $1 \%$ bovine serum albumin (Organon, Teknika, Boxtel, The Netherlands). Preparations of the cell suspensions were made in a cytocentrifuge (Shandon). Cytospin slides of BAL cells were stained with May-Grünwald-Giemsa (Merck, Darmstadt, Germany) for cell differential counts. At least 1000 cells were counted.

\section{STATISTICAL ANALYSIS}

Cox's proportional hazards model was used for analysing the dependency of mortality on the risk factors. ${ }^{16}$ As entry time we used the time at which BAL was performed. The end point was death due to all causes. The follow up ended in September 1992. As explanatory variables the following were considered: the percentages and absolute cell numbers of alveolar macrophages, lymphocytes, neutrophils, eosinophils, and mast cells in BAL fluid samples and their quadratic terms. Additionally, we also considered the effects of age, sex, smoking, and corticosteroid therapy at the time BAL was performed. The contribution of these variables to the model was tested by means of the likelihood ratio test.

The Mann-Whitney U test was used to evaluate differences in the cellular analysis of BAL fluid samples between patients with IPF and the control subjects. The same test was used to evaluate the results between different categories of patients with IPF, constituted by smoking and corticosteroid therapy at the time BAL was performed. A $p$ value less than 0.05 was considered to be significant.

\section{Results}

FOLLOW UP

During the follow up period 24 patients died, their mean survival being 3.7 years (range $0 \cdot 1-12 \cdot 2$ years). Fourteen patients died from respiratory insufficiency due to pulmonary fibrosis, five died from causes associated with pulmonary fibrosis (three from pulmonary infection, one from pulmonary embolism, one from lung cancer). Three patients died due to cardiovascular diseases and two from other causes. At the end of the follow up period (September 1992) 25 patients were still alive. Their follow up period ranged from $2 \cdot 6$ to $12 \cdot 1$ years (mean $8 \cdot 9$ ). No patients were lost to follow up.

Patients were treated by a team of pulmonary physicians. All patients were initially treated with high doses of corticosteroids for several weeks. The maintenance of treatment depended on the clinical course. Patients with rapid progression of disease (decline in lung function, shortness of breath at rest and/or hypoxia within three months after corticosteroid therapy was started, or within three months after the dose of corticosteroids was increased to $50 \mathrm{mg}$ daily) were additionally treated with azathioprine or cyclophosphamide. In patients who were stable the corticosteroid treatment was reduced to a maintenance level of between 5 and $10 \mathrm{mg}$ 
Table 2 Absolute numbers of cells in bronchoalveolar lavage fluid samples obtained from patients with idiopathic pulmonary fibrosis $(I P F)(n=49)$ and control subjects $(n=30)$

\begin{tabular}{|c|c|c|c|c|}
\hline & \multicolumn{2}{|l|}{ Non-smokers } & \multicolumn{2}{|l|}{ Smokers } \\
\hline & $I P F$ & Controls & $I P F$ & Controls \\
\hline $\begin{array}{l}\text { n } \\
\text { Total cell count } \\
\text { Alveolar mcarophages } \\
\text { Lymphocytes } \\
\text { Neutrophils } \\
\text { Eosinophils } \\
\text { Mast cells }\end{array}$ & $\begin{array}{l}31 \\
18 \cdot 6(10 \cdot 6-31 \cdot 0) \\
11.9(7 \cdot 7-17 \cdot 0) \\
1.0(0 \cdot 5-2 \cdot 7) \\
1 \cdot 4(0 \cdot 4-2 \cdot 8) \\
0 \cdot 8(0 \cdot 1-2 \cdot 9) \\
0.03(0 \cdot 00-0 \cdot 08)\end{array}$ & $\begin{array}{l}15 \\
8 \cdot 7(7 \cdot 9-11 \cdot 0) \\
7 \cdot 9(6 \cdot 7-9 \cdot 3) \\
1 \cdot 0(0 \cdot 5-1 \cdot 2) \\
0 \cdot 1(0 \cdot 0-0 \cdot 2) \\
0 \cdot 0(0 \cdot 0-0 \cdot 0) \\
0 \cdot 00(0 \cdot 00-0.04)\end{array}$ & $\begin{array}{l}18 \\
40.5(29 \cdot 7-59 \cdot 9) \\
31.6(12 \cdot 8-49 \cdot 8) \\
0.7(0 \cdot 3-2 \cdot 3) \\
1.9(0 \cdot 7-7 \cdot 3) \\
1.2(0 \cdot 3-3 \cdot 2) \\
0.03(0 \cdot 00-0.08)\end{array}$ & $\begin{array}{l}15 \\
23 \cdot 1(12 \cdot 4-31 \cdot 0) \\
22 \cdot 5(11 \cdot 4-28 \cdot 5) \\
0.9(0 \cdot 5-1 \cdot 2) \\
0 \cdot 1(0 \cdot 0-0 \cdot 3) \\
0 \cdot 1(0 \cdot 0-0 \cdot 1) \\
0.00(0 \cdot 00-0.00)\end{array}$ \\
\hline
\end{tabular}

Data are expressed as median absolute numbers of cells $\times 10^{4} / \mathrm{ml}$ with the interquartile ranges in parentheses.

prednisone daily. In patients whose clinical condition improved, further effort was made to minimise the steroid dose. Fourteen of the 19 patients who died from causes associated with pulmonary fibrosis were treated with cytotoxic drugs. Only three of the 25 patients still alive at the end of the follow up were treated with cytotoxic drugs.

\section{CELLULAR ANALYSIS}

The absolute numbers of neutrophils, eosinophils, and mast cells in BAL fluid samples of the patients with IPF were significantly higher than the control subjects $(p<0.001, p<0.001$ and $\mathrm{p}<0.02$, respectively) when the smoking history was taken into account. The absolute numbers of alveolar macrophages were increased only in non-smoking IPF patients $(p<0.05)$, whereas the absolute numbers of lymphocytes did not differ significantly between IPF patients and controls. The percentages of neutrophils, eosinophils, and mast cells of patients with IPF were significantly higher $(p<0.001, p<0.001$ and $p<0.02)$ than controls, whereas the percentage of alveolar macrophages was significantly lower $(p<0 \cdot 05)$. The percentage of lymphocytes of the IPF patients did not differ significantly from the control subjects. Because of a skewed distribution, the absolute cell numbers in BAL fluid of the patients with IPF are expressed as median values, which are listed in table 2, together with the data obtained from the control subjects. The percentages of the differential cell count in BAL fluid samples of the IPF patients and the control subjects are shown in table 3.

\section{SURVIVAL ANALYSIS (COX'S PROPORTIONAL HAZARDS MODEL)}

A negative relationship was found between survival and the absolute numbers as well as the percentages of eosinophils in BAL fluid samples obtained from IPF patients. Both models, one containing the absolute number of eosinophils and their quadratic terms, the other the percentages of eosinophils and their quadratic terms, were significant. Figure 1A shows the graph which expresses the mortality rate ratio as a function of the absolute numbers of eosinophils. The graph expressing the mortality rate ratio as a function of the percentage of eosinophils is shown in fig 1B. The corresponding coefficients, standard errors, and $\mathrm{p}$ values of both models are listed in table 4 .

The absolute numbers and the percentages of alveolar macrophages, lymphocytes, neutrophils, and mast cells did not show a significant relationship with survival.

No significant relationship was found between sex and survival in patients with IPF, between smoking and survival, nor for corticosteroid therapy at the time BAL was performed. The effect of age on mortality was

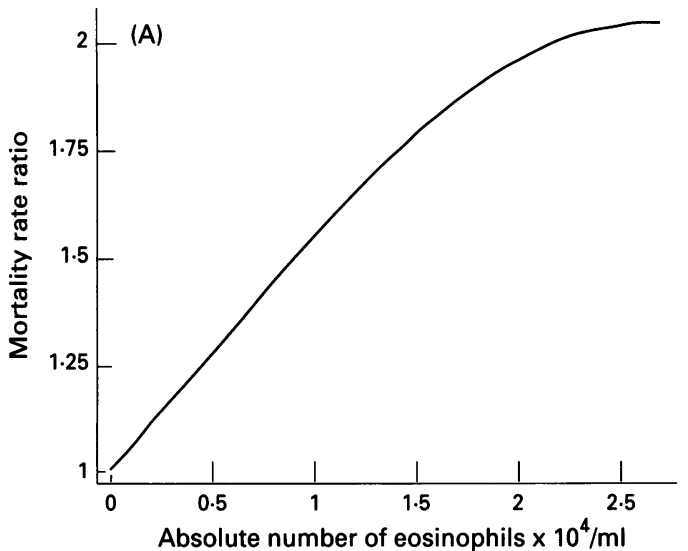

Figure $1 A$ (A) Function $f(x)$ which expresses the mortality rate ratio as a function of absolute numbers of eosinophils in bronchoalveolar lavage fluid samples obtained from patients with idiopathic pulmonary fibrosis $(x=a b s o l u t e$ number of eosinophils expressed as $10^{4}$ cells $/ \mathrm{ml} ; x=0$ is taken as the reference value where the rate equals 1$) . f(x)=e^{-0.1009 x^{2}+0.5366 x}$ (B) Function $g(x)$ which expresses the mortality rate ratio as a function of the percentage of eosinophils of the total cell count in bronchoalveolar lavage fluid samples obtained from patients with idiopathic pulmonary fibrosis $(x=$ percentage of eosinophils, $x=0$ is taken as the reference value where the rate equals 1$) . g(x)=e\left(-0.5833 \times 10^{-2}\right) x^{2}+0.1499 x$. 
Table 3 Percentages of cells in bronchoalveolar lavage fluid samples obtained from patients with idiopathic pulmonary fibrosis (IPF) $(n=49)$ and control subjects $(n=30)$

\begin{tabular}{|c|c|c|c|c|}
\hline & \multicolumn{2}{|l|}{ Non-smokers } & \multicolumn{2}{|l|}{ Smokers } \\
\hline & $I P F$ & Controls & $I P F$ & Controls \\
\hline $\begin{array}{l}\text { n } \\
\text { Alveolar } \\
\text { macrophages }\end{array}$ & $\begin{array}{l}31 \\
66 \cdot 7(3 \cdot 2)^{*}\end{array}$ & $\begin{array}{l}15 \\
87 \cdot 0(1 \cdot 4)\end{array}$ & $\begin{array}{l}18 \\
73 \cdot 5(3 \cdot 2) \dagger\end{array}$ & $\begin{array}{l}15 \\
91 \cdot 6(2 \cdot 3)\end{array}$ \\
\hline $\begin{array}{l}\text { Lymphocytes } \\
\text { Neutrophils } \\
\text { Eosinophils } \\
\text { Mast cells }\end{array}$ & $\begin{array}{l}12.4(2 \cdot 8) \\
12.0(1 \cdot 8)^{*} \\
8.9(2 \cdot 2)^{*} \\
0.28(0.06)^{*}\end{array}$ & $\begin{array}{l}11.0(1.4) \\
1.6(0.4) \\
0.3(0.1) \\
0.07(0.03)\end{array}$ & $\begin{array}{l}3 \cdot 7(1 \cdot 1) \\
14 \cdot 5(5 \cdot 3) \# \\
8 \cdot 1(3 \cdot 2) \# \\
0 \cdot 22(0 \cdot 11) \dagger\end{array}$ & $\begin{array}{l}6 \cdot 8(2 \cdot 2) \\
1 \cdot 2(0 \cdot 4) \\
0 \cdot 4(0 \cdot 1) \\
0 \cdot 02(0 \cdot 01)\end{array}$ \\
\hline
\end{tabular}

Data are expressed as mean (SE). ${ }^{*} \mathrm{p}<0.01$ IPF non-smokers $v$ control non-smokers (Mann Whitney $U$ test). \# $p<0.01$ IPF smokers $v$ control smokers (Mann-Whitney $U$ test). $+p<0.05$ IPF smokers $v$ control smokers (Mann-Whitney U test).

Table 4 Estimated coefficients, standard errors (SE) and $p$ values belonging to the mortality hazard function of the absolute number of eosinophils (function $f(x)$; model $1 A$ ) and of the percentage of eosinophils (function $g(x)$; model 1B) using Cox's proportional hazard survival analysis, concerning patients with idiopathic pulmonary fibrosis $(n=49)$

\begin{tabular}{|c|c|c|c|c|}
\hline & & Coefficient & $S E$ & $p$ value \\
\hline $\begin{array}{l}\text { Model 1A } \\
\left(\text { cells } \times 10^{4} / \mathrm{ml}\right) \\
\text { Model 1B } \\
\text { (percentage) }\end{array}$ & $\begin{array}{l}\text { Eosinophils } \\
\text { Eosinophils } \\
\text { Eosinophils } \\
\text { Eosinophils }\end{array}$ & $\begin{array}{l}0.5366 \\
-0.1009 \\
0.1499 \\
-0.5833 \times 10^{-2}\end{array}$ & $\left.\begin{array}{l}0.352 \\
0.674 \times 10^{-1} \\
0.804 \times 10^{-1} \\
0.332 \times 10^{-2}\end{array}\right\}$ & 0.037 \\
\hline
\end{tabular}

$f(x)=\mathrm{e}^{-0.1009 x^{2}+0.5366 x}$

$g(x)=\mathrm{e}^{\left(-0.5833 \times 10^{-2}\right) x^{2}+0.1499 x}$

significant in a univariate model $(\mathrm{p}<0 \cdot 05)$. In a model which includes age together with the absolute numbers of eosinophils and their quadratic terms, both variables lost their significant effect. When age was included in a model with the percentage of eosinophils and their quadratic terms, both variables also lost their significant effect. No relationship was found between eosinophils and survival.

\section{Discussion}

In this study a negative relationship was found between the absolute numbers as well as the percentage of eosinophils in BAL fluid samples obtained from patients with IPF and survival. No relationship was demonstrated between survival and the absolute numbers or the percentages of any other cell type in BAL fluid.

In previous studies by other groups BAL eosinophilia has been associated with a poor response to therapy and clinical deterioration. ${ }^{8911} \mathrm{~A}$ possible role for the eosinophil in IPF has therefore been suggested. ${ }^{1718}$ Moreover, increased levels of eosinophil-derived eosinophilic cationic protein (ECP) have been found in BAL fluid from patients with IPF. ${ }^{19}$ ECP is a very toxic protein, capable of damaging the lung tissue. ${ }^{2021}$ Eosinophils may also be involved in the proliferation of fibroblasts, as in vitro fibroblast DNA synthesis induced by eosinophil-derived factors has been described. $^{22}$ In one study, however, no relationship was found between initial BAL eosinophilia and response to treatment but a higher BAL eosinophil content was correlated with more severe initial clinical impairment. ${ }^{12}$ As not all patients in our study had pulmonary function tests shortly before BAL, we were not able to incorporate the results of indices such as TLC or TLCO as a covariate in the survival analysis to adjust for the severity of the disease. In a separate study we investigated lung biopsy material from 29 IPF patients, comparing the cellularity and the degree and the extent of fibrosis with the BAL cell profile. No relationship was found between any of the cell types (including eosinophils) and the histological picture (data not shown). This is consistent with the study by Watters et al who found no correlation between BAL fluid eosinophil content and histopathological abnormalities, although a possible relationship between BAL eosinophilia and the presence of honeycombing was suggested. ${ }^{12}$ In patients with fibrosing alveolitis in systemic sclerosis, which is histologically identical to lone idiopathic pulmonary fibrosis, Wells and coworkers studied the relationship between BAL findings and the pattern and extent of the disease, judged by thin section computed tomographic (CT) scanning. ${ }^{23}$ Significantly increased BAL eosinophil counts were found in early as well as in advanced disease, with a relationship between the percentage of eosinophils and the extent of a ground glass pattern on CT, suggesting inflammatory histological appearances. However, survival was better in fibrosing alveolitis associated with systemic sclerosis than in idiopathic pulmonary fibrosis. ${ }^{24}$ Fibrosing alveolitis may have different pathogenic mechanisms in the two diseases, causing the difference in survival. Whether eosinophils are (partly) responsible for the damage to the alveoli in IPF or BAL eosinophilia reflects advanced disease remains to be established.

In this present study there was a negative relationship between age and survival. When the absolute number or the percentage of eosinophils was included as an explanatory variable in the model, together with the variable of age, both variables lost their significant effect. No relationship was found between eosinophils and survival. In both models the shape of the relationship of mortality with eosinophils does not essentially change, either with or without age as an explanatory variable in the model. It is likely that the sample size is too small to reach statistical significance in a model with more explanatory variables.

One of the limitations of the study is that approximately $40 \%$ of the patients were receiving corticosteroids at the time BAL was performed. Although no relationship was demonstrated between corticosteroid treatment at the time BAL was performed and survival, therapy may have influenced BAL findings. ${ }^{10}$ Survival analysis of the untreated group (27 patients) showed a tendency for a negative relationship between the absolute numbers of eosinophils and survival, but the results were not significant. It is likely that the number of patients is too small to reach statistically significant results in this model.

Schwartz et al did not find a relationship between BAL findings and survival in IPF patients, ${ }^{7}$ although a higher concentration of lymphocytes appeared to be independently associated with slightly improved survival in a subgroup of their patients. They studied 74 patients, approximately $40 \%$ of whom were also receiving corticosteroid treatment, one third in combination with cyclophosphamide. In their 
study the male/female ratio was almost similar to that described here, while the average age was slightly higher. There were no racial differences between both groups. They analysed survival from onset of symptoms and not from the time BAL was performed. This was done in order to adjust for the variable length of time between onset of symptoms and time of diagnosis. If we analysed our data with survival from the time of onset of symptoms, we found not only a relationship between the absolute number and percentage of eosinophils and survival but also a relationship between the absolute number and percentage of neutrophils and survival. It is plausible that response of treatment and progression of disease may have altered BAL findings. Schwartz and coworkers performed a hierarchical multivariate analysis on the factors that were found to be significantly associated with diminished survival in IPF, to assess the relative independence of these associated factors. Since the number of patients in our study was too small, we were not able to perform such an analysis.

In contrast to our study, Schwartz et al did not demonstrate a negative relationship between age and survival, but found male gender to be predictive of diminished survival. Previously Turner-Warwick and coworkers demonstrated a negative relationship between age and survival as well as between male gender and survival. ${ }^{25}$ In this last study, however, patients with fibrosis associated with connective tissue disorders were also included. No obvious reasons were found to explain the discrepancies regarding male gender and age between the study by Schwartz et al and the present study.

The effect of smoking on survival in this study was not significant, which is in agreement with two previous studies. ${ }^{2526}$ Although we may expect that smoking had influenced BAL findings, it remains to be established whether smoking contributes to the fibrotic reaction in IPF.

To our knowledge, no study has investigated the relationship between the absolute number or the percentage of mast cells in BAL fluid and the clinical course in pulmonary fibrosis, although some studies suggest a role for mast cells in IPF. Increased levels of histamine in BAL fluid were correlated with more pronounced fibrosis in lung biopsy specimens from IPF patients in one study. ${ }^{13}$ Mast cells have been found in large numbers, particularly in thickened, fibrous alveolar septa, ${ }^{27}$ and are found closely apposed to fibroblasts as in normal lung tissue. ${ }^{28} \mathrm{~A}$ relationship has recently been described between the percentage of mast cells in BAL fluid samples and the gradation of pulmonary fibrosis in patients with interstitial lung diseases. ${ }^{29}$ Although in our study the absolute numbers as well as the percentage of mast cells were significantly increased in the IPF patients compared with the control subjects, we did not demonstrate a relationship between the percentage or the number of mast cells and survival in IPF patients. It is possible that the effect of mast cells on the fibrotic process is too small to affect survival. It has also been suggested that they play a minor role since pulmonary fibrosis can also be induced by bleomycin in mice genetically deficient in mast cells. ${ }^{30}$

In summary, this study shows that there is a negative relationship between the absolute number as well as the percentage of eosinophils in BAL fluid samples and survival in IPF patients. However, we acknowledge that patients with IPF present at different stages of the disease process and that treatment may have influenced BAL findings. For further investigation prospective studies are necessary with BAL preferably being performed before treatment is started.

We gratefully acknowledge Marjolein Drent for her advice and helpful discussions during the preparation of this manuscript and Els Tuenter and Mona Donckerwolcke-Bogaert for their and Els Tuenter

This study was supported by a grant of Glaxo BV, The Netherlands.

1 Bronchoalveolar lavage constituents in healthy individuals, idiopathic pulmonary fibrosis, and selected comparison groups. The BAL Cooperative Group Steering Committee. Am Rev Respir Dis 1990;141:S169-202.

2 Drent M, Mulder PG, Wagenaar SjSc, Hoogsteden HC, van Velzen Blad $\mathbf{H}$, van den Bosch JMM. Differences in van Velzen Blad $H$, van den Bosch JMM. Differences in by discriminant analysis. Eur Respir $\mathcal{f}$ 1993;6:803-10.

3 Rankin JA, Kaliner M, Reynolds HY. Histamine levels in bronchoalveolar lavage from patients with asthma, sarcoidosis, and idiopathic pulmonary fibrosis. $\mathcal{F}$ Allergy Clin Immunol 1987;79:371-7.

4 Haslam PL, Dewar A, Butchers P, Primett ZS, NewmanTaylor A, Turner-Warwick M. Mast cells, atypical lymphocytes, and neutrophils in bronchoalveolar lavage in extrinsic allergic alveolitis. Comparison with other interstitial lung diseases. Am Rev Respir Dis 1987;135:35-47.

5 Agius RM, Godfrey RC, Holgate ST. Mast cell and histamine content of human bronchoalveolar lavage fluid. Thorax 1985;40:760-7.

6 Walls AF, Bennett AR, Godfrey RC, Holgate ST, Church MK. Mast cell tryptase and histamine concentrations in bronchoalveolar lavage fluid from patients with interstitial lung disease. Clin Sci Colch 1991;81:183-8.

7 Schwartz DA, Helmers RA, Galvin JR, Van Fossen DS Frees KL, Dayton CS, et al. Determinants of survival in idiopathic pulmonary fibrosis. Am $\mathcal{f}$ Respir Crit Care Med 1994;149:450-4.

8 Haslam PL, Turton CW, Lukoszek A, Salsbury AJ, Dewar A, Collins JV, et al. Bronchoalveolar lavage fluid cell counts in cryptogenic fibrosing alveolitis and their relation to therapy. Thorax 1980;35:328-39.

9 Rudd RM, Haslam PL, Turner-Warwick M. Cryptogenic fibrosing alveolitis. Relationships of pulmonary physiology and bronchoalveolar lavage to response to treatment and prognosis. Am Rev Respir Dis 1981;124:1-8.

prognosis. Am Rev Respir Dis 1981;124:1-8.
10 Turner-Warwick M, Haslam PL. The value of serial bronchoalveolar lavages in assessing the clinical progress of patients with cryptogenic fibrosing alveolitis. Am Rev of patients with cryptogenic
Respir Dis 1987;135:26-34.

11 Peterson MW, Monick M, Hunninghake GW. Prognostic role of eosinophils in pulmonary fibrosis. Chest 1987;92: 51-6.

12 Watters LC, Schwarz MI, Cherniack RM, Waldron JA Dunn TL, Stanford RE, et al. Idiopathic pulmonary fibrosis. Pretreatment bronchoalveolar lavage cellular constituents and their relationships with lung histopathology and clinical response to therapy. Am Rev Respir Dis 1987 135:696-704.

13 Haslam PL, Cromwell O, Dewar A, Turner-Warwick M. Evidence of increased histamine levels in lung lavage fluids from patients with cryptogenic fibrosing alveolitis. Clin from patients with cryptogenic

14 Tomioka M, Goto T, Lee TD, Bienenstock J, Befus AD. Isolation and characterization of lung mast cells from rats with bleomycin-induced pulmonary fibrosis. Immunology 1989;66:439-44.

15 Aldenborg F, Nilsson K, Jarlshammar B, Bjermer L, Enerback L. Mast cells and biogenic amines in radiationinduced pulmonary fibrosis. Am $\mathcal{f}$ Respir Cell Mol Bio 1993;8:112-7.

16 Cox DR. Regression models and life-tables. $\mathcal{F} R$ Stat $B$ 1972;34:187-202.

17 Venge $P$. What is the role of the eosinophil? Thorax 1990 45:161-3.

$18 \mathrm{Libby} \mathrm{DM}$. The eosinophil in idiopathic pulmonary fibrosis. Chest 1987;92:7-8.

19 Kroegel C, Matthys H, Costabel U. Morphology and density features of eosinophil leukocytes in eosinophilic pneumonia. A case report. Clin Invest 1992;70:447-53.

20 Davis WB, Fells GA, Sun XH, Gadek JE, Venet A, Crystal avis WB, Fells GA, Sun XH, Gadek JE, Venet A, Crysta RG. Eosinophil-mediated injury to lung parenchymal cells and interstitial matrix. A possible role for eosinophils in
chronic inflammatory disorders of the lower respiratory tract. $\mathcal{F}$ Clin Invest 1984;74:269-78. 
21 Venge P, Dahl R, Fredens K, Peterson CG. Epithelial injury by human eosinophils. Am Rev Respir Dis 1988;138:S54-7. 22 Pincus SH, Ramesh KS, Wyler DJ. Eosinophils stimulate fibroblast DNA synthesis. Blood 1987;70:572-4.

23 Wells AU, Hansell DM, Rubens MB, Cullinan P, Haslam PL, Black CM, et al. Fibrosing alveolitis in systemic sclerosis. Bronchoalveolar lavage findings in relation to computed tomographic appearance. Am $\mathcal{F}$ Respir Crit Car Med 1994;150:462-8.

24 Wells AU, Cullinan P, Hansell DM, Rubens MB, Black CM, Newman-Taylor AJ, et al. Fibrosing alveolitis associated with systemic sclerosis has a better prognosis than lone cryptogenic fibrosing alveolitis. Am 7 Respir Crit Care Med 1994;149:1583-90.

25 Turner-Warwick M, Burrows B, Johnson A. Cryptogenic fibrosing alveolitis: clinical features and their influence on survival. Thorax 1980;35:171-80.

26 Cremoux de $\mathrm{H}$, Bernaudin J-F, Laurent $\mathrm{P}$, Brochard $\mathrm{P}$,
Bignon J. Interactions between cigarette smoking and the natural history of idiopathic pulmonary fibrosis. Chest 1990;98:71-6.

27 Kawanami O, Ferrans VJ, Fulmer JD, Crystal RG. Ultrastructure of pulmonary mast cells in patients with fibrotic lung disorders. Lab Invest 1979;40:717-34.

28 Heard BE, Dewar A. Corrin B. Apposition of fibroblasts to mast cells and lymphocytes in normal human lung and in cryptogenic fibrosing alveolitis. Ultrastructure and cell perimeter measurements. F Pathol 1992;166:303-10.

29 Pesci A, Bertorelli G, Gabrielli M, Olivieri D. Mast cells in fibrotic lung disorders. Chest 1993;103:989-96.

30 Mori H, Kawada K, Zhang P, Uesugi Y, Sakamoto O, Koda A. Bleomycin-induced pulmonary fibrosis in genetically mast cell-deficient WBB6F1-W/Wv mice and mechanism of the suppressive effect of tranilast, an antiallergic drug inhibiting mediator release from mast cells, on fibrosis. Int Arch Allergy Appl Immunol 1991;95:195-201. 